\title{
Mortality after acute myocardial infarction is lower in metropolitan regions than in non-metropolitan regions
}

\author{
Huy Dinh Vu, Richard F Heller, Lynette L-Y Lim, Catherine D’Este, Rachel L O'Connell
}

\begin{abstract}
Study objectives-To compare inhospital mortality for acute myocardial infarction (AMI) between metropolitan and nonmetropolitan hospitals after adjustment for patients' severity; to examine the role of the use of effective cardiac medications in the possible mortality difference between these types of hospital.

Design-Retrospective cohort study. Setting-47 acute public hospitals in metropolitan and non-metropolitan areas of New South Wales, Australia, taking part in the Acute Cardiac Care Project based on medical record review.

Patients-1665 patients with principal discharge diagnosis of AMI from February to June 1996.

Main results-There was no difference in crude mortality rate (assessed as seven day mortality) between metropolitan and non-metropolitan hospitals $(11.0 \%$ compared with $10.7 \%$ respectively, $p=0.893$ ). After adjustment for severity in a logistic regression model, the odds of death in non-metropolitan hospitals was significantly higher than in metropolitan hospitals (odds ratio $=1.90 ; 95 \%$ CI $1.21,3.23$ ). The addition of the use of effective cardiac medications to the model resulted in the difference between hospital type becoming non-significant (odds ratio $=1.09 ; 95 \%$ CI 0.57, 2.07).

Conclusions-Inhospital mortality in non-metropolitan hospitals was higher than that in metropolitan hospitals, after adjustment for patients' severity. This might partly be explained by the difference in use of effective cardiac medications between hospital type.

(F Epidemiol Community Health 2000;54:590-595)
\end{abstract}

Epidemiology and

Biostatistics, The

University of

Newcastle, David

Maddison Clinical

Sciences Building,

Royal Newcastle

Hospital, Newcastle

NSW 2300, Australia

$\mathrm{H}$ Dinh Vu

R F Heller

L L-Y Lim

C D'Este

R L O'Connell

Correspondence to: Professor Heller

(rfhcceb@ibm.net)

Accepted for publication 1 February 2000 quality of care for conditions such as acute myocardial infarction (AMI). ${ }^{6}$ For patients with AMI, previous studies have shown that there is considerable variation in mortality between hospital types ${ }^{7}$ and between rural and urban hospitals, ${ }^{8}$ after adjustment for patients' severity. The difference in mortality of patients with AMI treated by cardiologists compared with those treated by general practitioners has also been examined. ${ }^{9} 10$

In Australia, where the population density varies markedly across the country, there is considerable variation in access to health services across the country. ${ }^{11}$ Dobson et $a l^{12}$ compared the mortality from AMI between Perth and Newcastle (on the west and east coast respectively), and we have explored the differences within one region in the management of AMI. ${ }^{13}$ However, little is known about the difference in hospital mortality between hospital types. In this study, we used data from the Acute Cardiac Care Project, which examined hospital care and outcomes for AMI in representative public hospitals across the spectrum of care throughout the State of New South Wales to compare inhospital mortality from AMI between metropolitan and nonmetropolitan hospitals. We tested the hypothesis that seven day mortality was different between non-metropolitan and metropolitan hospitals after adjustment for patient severity. We also examined the use of cardiac medications, which might play a part in the possible variation in mortality between the two hospital types.

\section{Methods}

DATA SOURCES

We used the data from the Acute Cardiac Care Project that reviewed medical records for patients admitted to $47 \mathrm{NSW}$ public hospitals between 1 February and 30 June 1996, with principal discharge diagnosis code of ICD9-CM 410 (AMI); 411.4, 411.8, 413 (angina) and 786.5 (chest pain).

In the project, hospitals were classified into six groups according to the NSW Health Department 1994/95 classification system ${ }^{14}$ : Principal Referral, Major Metropolitan Referral, Major Non-Metropolitan Referral, District Metropolitan, Large District Non-Metropolitan and Small District Non-Metropolitan. Because of the small number of eligible patients, Community Acute and Ungrouped Acute hospitals were excluded (hospitals had been classified as ungrouped because they had no appropriate peer group, because of a single focus specialty or because of 
unusual administrative arrangements). Participating hospitals included all Principal Referral $(n=8)$, Major Metropolitan Referral ( $n=5)$ and Major Non-Metropolitan Referral $(n=6)$ hospitals and a random sample comprising 6 of the 21 District Metropolitan, 6 of the 12 Large District Non-Metropolitan and 16 of the 31 Small District Non-Metropolitan. All approached hospitals agreed to participate in the project.

Medical records were reviewed, by specially trained coronary care or research nurses, for patient demographics, clinical signs and symptoms, management and follow up measures. Data were also linked to the National Death Index, a national database containing up to date information on all deaths registered in Australia, to determine which patients had died.

The project was approved by the NSW Statewide Ethics Committee, the University of Newcastle Research Ethics Committee, and

Table 1 Patients characteristics by hospital type. (Numbers are percentages unless otherwise indicated)

\begin{tabular}{|c|c|c|c|}
\hline & $\begin{array}{l}\text { Metropolitan } \\
(n=1048)\end{array}$ & $\begin{array}{l}\text { Non-metropolitan } \\
(n=617)\end{array}$ & $p$ value \\
\hline Transferred in $\mathrm{n}(\%)$ & $95(9)$ & $138(23)$ & 0.004 \\
\hline Male sex & 64 & 68 & 0.069 \\
\hline \multicolumn{4}{|l|}{ Age group } \\
\hline$\leqslant 60$ & 26 & 31 & 0.007 \\
\hline $61-70$ & 25 & 28 & \\
\hline$>70$ & 49 & 41 & \\
\hline \multicolumn{4}{|l|}{ Pulse rate } \\
\hline$<80$ & 47 & 48 & \\
\hline $80-<110$ & 39 & 43 & \\
\hline$\geqslant 110$ & 14 & 10 & 0.013 \\
\hline \multicolumn{4}{|l|}{ Systolic BP } \\
\hline$<100$ & 8 & 6 & \\
\hline $100-180$ & 81 & 83 & \\
\hline$>180$ & 12 & 11 & 0.310 \\
\hline Raised JVP & 11 & 7 & 0.059 \\
\hline Basal crepitations & 38 & 28 & 0.024 \\
\hline Pulmonary oedema & 30 & 25 & 0.129 \\
\hline Admission in cardiac arrest & 7 & 5 & 0.154 \\
\hline \multicolumn{4}{|l|}{ ST elevation on ECG } \\
\hline Yes & 53 & 59 & \\
\hline No & 40 & 39 & \\
\hline Not recorded & 6 & 2 & 0.108 \\
\hline \multicolumn{4}{|l|}{ ST depression on ECG } \\
\hline Yes & 56 & 68 & \\
\hline No & 37 & 30 & \\
\hline Not recorded & 7 & 2 & 0.010 \\
\hline \multicolumn{4}{|l|}{ LBBB on ECG } \\
\hline Yes & 7 & 5 & \\
\hline No & 82 & 93 & \\
\hline Not recorded & 11 & 3 & 0.006 \\
\hline \multicolumn{4}{|l|}{ History } \\
\hline AMI & 26 & 22 & \\
\hline Angina or revascularisation & 17 & 16 & \\
\hline No history & 57 & 62 & 0.316 \\
\hline Diabetes & 13 & 15 & 0.420 \\
\hline \multicolumn{4}{|l|}{ Infarct position } \\
\hline anterior & 29 & 31 & \\
\hline inferior & 34 & 37 & \\
\hline other & 25 & 19 & \\
\hline Not recorded & 12 & 14 & 0.358 \\
\hline Cardiomegaly on radiography & 25 & 23 & 0.562 \\
\hline \multicolumn{4}{|l|}{ Principal symptom precipitating admission } \\
\hline Chest pain & 77 & 82 & \\
\hline Other & 23 & 18 & 0.102 \\
\hline Reinfarction within 24 hours & 7 & 6 & 0.213 \\
\hline Recurrent chest pain within 24 hours & 37 & 40 & 0.625 \\
\hline \multicolumn{4}{|c|}{ Health insurance: patient classification for this admission } \\
\hline Chargeable & 21 & 19 & \\
\hline Veterans affairs - chargeable & 7 & 7 & \\
\hline Non-chargeable & 72 & 73 & 0.745 \\
\hline \multicolumn{4}{|l|}{ Hospital treatment } \\
\hline Ace inhibitor & 50 & 42 & 0.068 \\
\hline Aspirin & 88 & 81 & 0.004 \\
\hline$\beta$ blocker & 57 & 47 & 0.011 \\
\hline Intravenous heparin & 79 & 64 & 0.007 \\
\hline Intravenous nitrate & 39 & 37 & 0.791 \\
\hline Thrombolysis & 36 & 41 & 0.138 \\
\hline
\end{tabular}

individual hospital or Area Health Service committees where appropriate.

STUDY SAMPLES

Our study included the patients with primary discharge diagnosis of AMI from the Acute Cardiac Care Project (code ICD-9-CM 410). To identify roughly comparable numbers in each hospital type, all patients admitted to Major Non-Metropolitan, District Metropolitan, Large District Non-Metropolitan and Small District Non-Metropolitan hospitals and a random sample of 50 patients admitted to each Principal Referral hospital and 80 patients admitted to each Major Metropolitan Referral hospital were selected. For 38 patients with multiple admissions within the same hospital, only the first admission was used in the analysis.

\section{OUTCOME AND STUDY FACTORS}

The diagnosis of AMI was made by the hospital clinicians, based on symptoms, changes in electrocardiography (ECG) findings and enzyme activities, and coded from the hospital separation data. Mortality information was obtained from the medical record, the computerised hospital separation data and the National Death Index. Mortality at seven days rather than inhospital mortality was taken as a common end point to allow assessment of mortality for patients discharged or transferred. This resulted in 29 patients who died in hospital later than seven days after admission being classified as non-fatal and seven patients being included who died after transfer and would otherwise have been missed. Seven day mortality is thus used as a proxy for inhospital mortality.

To reflect the care received by people living in metropolitan or non-metropolitan catchment areas, we categorised hospitals as metropolitan (including Principal Referral, Major Metropolitan Referral and District Metropolitan) or non-metropolitan (including Major Non-Metropolitan Referral, Large District Non-Metropolitan and Small District NonMetropolitan).

Disease severity was measured by a set of severity variables that were based on reviewing the literature, ${ }^{15} 16$ and were selected from the clinical signs and symptoms within 24 hours from admission available from the hospital records. There are two reasons for choosing the 24 hour time period: (1) the patients' severity should be measured if possible before the treatment is provided by the hospital ${ }^{17}$; and (2) many patients die within 48 hours after admission. ${ }^{1}$ However, we believed that some conditions would probably not change over the time of observation, therefore if diabetes was recorded in the data, it was considered present at the time of admission. There were 19 severity variables (including demographic characteristics) selected: age, sex, insurance status, first recorded pulse rate, admission systolic blood pressure, raised jugular venous pressure (JVP), basal crepitations, pulmonary oedema (defined as pulmonary oedema on either clinical or radiological examination), cardiac arrest 
on admission, ST increase on ECG, ST depression on ECG, left bundle branch block on ECG, cardiomegaly on radiography, previous history of AMI, angina, or revascularisation, diabetes, infarct position, principal symptom precipitating admission and re-infarction or recurrent chest pain within 24 hours.

The American College of Cardiology/ American Heart Association (ACC/AHA) guidelines for the management of patients with $\mathrm{AMI}^{17}$ were used to select hospital treatment variables from the dataset. Only the cardiac medications verified to be effective (class 1 in the guidelines based on evidence available in 1996) were selected for the analysis: ACE inhibitors, aspirin, $\beta$ blockers, intravenous heparin, intravenous nitrates and thrombolysis.

\section{STATISTICAL ANALYSIS}

The survey commands in STATA (StataCorp, 1999, Statistical Software: Release 6.0), especially designed for use with complex survey data, were used to perform the analysis. Hospital type (six levels) was specified as the strata and the individual hospitals were specified as the primary sampling units. Pearson's $\chi^{2}$ test

Table 2 Results of logistic regression model predicting seven day mortality. Includes hospital type, transfer status, demographic and severity variables as independent variables

\begin{tabular}{|c|c|c|}
\hline Patient characteristic & Odds ratio $(95 \% \mathrm{CI})$ & $p$ value \\
\hline Non-metropolitan $v$ Metropolitan ${ }^{\star}$ & $1.90(1.21,3.23)$ & 0.018 \\
\hline Transfer yes $v$ no & $1.10(0.58,2.08)$ & 0.771 \\
\hline \multicolumn{3}{|l|}{ Age group } \\
\hline$\leqslant 60$ & $0.12(0.06,0.25)$ & $<0.001$ \\
\hline $61-70$ & $0.14(0.07,0.25)$ & $<0.001$ \\
\hline$>70$ & 1 & \\
\hline Sex (male $v$ female) & $0.54(0.35,0.83)$ & 0.006 \\
\hline \multicolumn{3}{|l|}{ Pulse } \\
\hline$<80$ & 1 & \\
\hline $80-<110$ & $1.57(0.96,2.54)$ & 0.069 \\
\hline$\geqslant 110$ & $1.09(0.53,2.22)$ & 0.812 \\
\hline \multicolumn{3}{|l|}{ Systolic blood pressure } \\
\hline$<100$ & $2.93(1.47,5.87)$ & 0.003 \\
\hline $100-180$ & 1 & \\
\hline$>180$ & $0.73(0.39,1.36)$ & 0.310 \\
\hline Raised JVP & $1.18(0.62,2.26)$ & 0.599 \\
\hline Lungs basal crepitations & $1.41(0.99,2.01)$ & 0.056 \\
\hline Pulmonary oedema & $1.66(1.03,2.65)$ & 0.036 \\
\hline Cardiac arrest & $6.29(2.68,14.75)$ & $<0.001$ \\
\hline \multicolumn{3}{|l|}{ ST increase } \\
\hline Yes & $3.02(1.88,4.87)$ & $<0.001$ \\
\hline No & 1 & \\
\hline Not recorded & $3.43(1.60,7.34)$ & 0.002 \\
\hline \multicolumn{3}{|l|}{ ST depression } \\
\hline Yes & $1.36(0.77,2.39)$ & 0.283 \\
\hline No & 1 & \\
\hline Not recorded & $2.68(0.85,8.40)$ & 0.089 \\
\hline \multicolumn{3}{|l|}{ LBBB } \\
\hline Yes & $1.24(0.63,2.46)$ & 0.523 \\
\hline No & 1 & \\
\hline Not recorded & $1.28(0.68,2.42)$ & 0.436 \\
\hline \multicolumn{3}{|l|}{ History } \\
\hline Previous AMI & $0.66(0.37,1.17)$ & 0.152 \\
\hline Angina or revascularisation & $1.11(0.64,1.93)$ & 0.696 \\
\hline No history & 1 & \\
\hline Diabetes & $1.18(0.70,2.01)$ & 0.528 \\
\hline \multicolumn{3}{|l|}{ Position } \\
\hline Anterior & 1 & \\
\hline Inferior & $0.80(0.43,1.51)$ & 0.487 \\
\hline Other & $1.55(0.73,3.30)$ & 0.245 \\
\hline Not recorded & $1.85(0.94,3.61)$ & 0.073 \\
\hline Cardiomegaly & $0.62(0.39,0.99)$ & 0.044 \\
\hline \multicolumn{3}{|c|}{ Principal symptom precipitating admission } \\
\hline Chest pain $v$ other & $0.58(0.34,1.01)$ & 0.053 \\
\hline Reinfarction & $5.61(2.91,10.83)$ & $<0.001$ \\
\hline Recurrent chest pain & $0.65(0.39,1.08)$ & 0.092 \\
\hline \multicolumn{3}{|l|}{ Insurance } \\
\hline Chargeable & 1 & \\
\hline Veterans affairs non-chargeable & $1.67(0.78,3.56)$ & 0.179 \\
\hline Non-chargeable & $2.38(1.50,3.78)$ & $<0.001$ \\
\hline
\end{tabular}

${ }^{\star}$ For non-transferred patients the odds ratio $(95 \% \mathrm{CI})$ was $1.58(0.95,2.63)$ while for transferred patients it was $9.74(1.32,71.95)$.
KEY POINTS

- Inhospital mortality after heart attack was $90 \%$ higher in hospitals serving nonmetropolitan than metropolitan areas, after adjusting for severity.

- The use of effective medications differed between hospital type and predicted inhospital mortality.

- The inequalities in health outcomes after heart attack associated with living in nonmetropolitan areas may be attributable to differences in use of effective medication.

was used to test for differences in baseline characteristics between patients treated in metropolitan and non-metropolitan hospitals and to identify which factors were associated with seven day mortality. Multivariate analysis was done using the logistic regression survey command, with seven day mortality as the outcome. Model 1 contained hospital type and transferred in status in addition to the 19 demographic/severity variables identified above to measure the difference in severity adjusted mortality between metropolitan and non-metropolitan hospitals. To determine whether the use of effective cardiac medications in hospitals influenced seven day mortality, a second model was developed by adding the treatment variables.

Ninety two observations with missing values were excluded from the logistic regression analyses, which were restricted to 1573 patients.

\section{Results}

BASIC CHARACTERISTICS OF THE STUDY PATIENTS There were 1665 patients treated at the 47 participating hospitals. Table 1 shows basic characteristics of the patients according to hospital location. Patients treated in metropolitan hospitals were older, more likely to have a pulse rate of 110 or more and basal crepitations. Patients in non-metropolitan hospitals were more likely to have been transferred in and had more ST depression on ECG. The use of aspirin, $\beta$ blockers and heparin was greater in metropolitan hospitals than in non-metropolitan hospitals.

\section{SEVEN DAY MORTALITY}

The crude mortality rates were $11.0 \%$ in metropolitan hospitals and $10.7 \%$ in nonmetropolitan hospitals $(\mathrm{p}=0.893)$. After adjustment for severity (table 2), the odds of seven day mortality in non-metropolitan hospitals was significantly higher than that in metropolitan hospitals (odds ratio $=1.90,95 \%$ CI 1.12, 3.23, $\mathrm{p}=0.018$ ).

Older age, female sex, low systolic blood pressure, pulmonary oedema, admitted in cardiac arrest, ST increase, suffering a reinfarction within 24 hours and being nonchargeable all predicted a higher seven day mortality. 
THE ROLE OF HOSPITAL TREATMENT IN THE DIFFERENCE IN MORTALITY BETWEEN THE METROPOLITAN AND NON-METROPOLITAN HOSPITALS

The influence of hospital treatment on mortality was assessed by adding the hospital treatment variables into the model (table 3 ). The inhospital use of ACE inhibitors, $\beta$ blockers and aspirin were all associated with a reduction in seven day mortality. After their inclusion in the model, there was no significant difference in mortality between metropolitan and nonmetropolitan hospitals (odds ratio $=1.09,95 \%$ CI $0.64,2.21, \mathrm{p}=0.581$ ).

THE TRANSFERRED IN PATIENTS

Twenty three per cent of the patients admitted into non-metropolitan and 9\% of those admitted to metropolitan hospitals had been transferred in from another hospital $(p=0.004)$. Almost all of these patients were transferred from a smaller to a larger hospital within metro-

Table 3 Results of logistic regression model with addition of treatment variables

\begin{tabular}{|c|c|c|}
\hline Patient characteristics & Odds ratio $(95 \% \mathrm{CI})$ & $p$ value \\
\hline Non-metropolitan $v$ Metropolitan ${ }^{\star}$ & $1.09(0.57,2.07)$ & 0.790 \\
\hline Transfer yes $v$ no & $1.19(0.64,2.21)$ & 0.581 \\
\hline \multicolumn{3}{|l|}{ Age group } \\
\hline$\leqslant 60$ & $0.11(0.05,0.25)$ & $<0.001$ \\
\hline $61-70$ & $0.14(0.08,0.25)$ & $<0.001$ \\
\hline$>70$ & 1 & \\
\hline Sex (male $v$ female) & $0.52(0.33,0.82)$ & 0.006 \\
\hline \multicolumn{3}{|l|}{ Pulse } \\
\hline$<80$ & 1 & \\
\hline $80-<110$ & $1.69(0.95,3.00)$ & 0.072 \\
\hline$\geqslant 110$ & $0.87(0.41,1.82)$ & 0.697 \\
\hline \multicolumn{3}{|l|}{ Systolic blood pressure } \\
\hline$<100$ & $1.98(0.99,3.93)$ & 0.052 \\
\hline $100-180$ & 1 & \\
\hline$>180$ & $0.68(0.34,1.36)$ & 0.270 \\
\hline Raised JVP & $1.62(0.88,2.98)$ & 0.120 \\
\hline Lungs basal crepitations & $1.21(0.81,1.81)$ & 0.333 \\
\hline Pulmonary oedema & $1.77(1.13,2.76)$ & 0.013 \\
\hline Cardiac arrest & $4.46(2.07,9.57)$ & $<0.001$ \\
\hline \multicolumn{3}{|l|}{ ST increase } \\
\hline Yes & $3.66(2.07,6.47)$ & $<0.001$ \\
\hline No & 1 & \\
\hline Not recorded & $5.12(2.29,11.44)$ & $<0.001$ \\
\hline \multicolumn{3}{|l|}{ ST depression } \\
\hline Yes & $1.32(0.73,2.39)$ & 0.348 \\
\hline No & 1 & \\
\hline Not recorded & $1.48(0.39,5.60)$ & 0.555 \\
\hline \multicolumn{3}{|l|}{ LBBB } \\
\hline Yes & $1.18(0.57,2.45)$ & 0.651 \\
\hline No & 1 & \\
\hline Not recorded & $0.99(0.50,1.97)$ & 0.972 \\
\hline \multicolumn{3}{|l|}{ History } \\
\hline Previous AMI & $0.51(0.26,0.98)$ & 0.043 \\
\hline Angina or revascularisation & $1.09(0.65,1.84)$ & 0.740 \\
\hline No history & 1 & \\
\hline Diabetes & $1.40(0.78,2.50)$ & 0.249 \\
\hline \multicolumn{3}{|l|}{ Position } \\
\hline Anterior & 1 & \\
\hline Inferior & $0.73(0.36,1.50)$ & 0.386 \\
\hline Other & $1.47(0.68,3.16)$ & 0.318 \\
\hline Not recorded & $1.44(0.70,2.98)$ & 0.317 \\
\hline Cardiomegaly & $0.60(0.37,0.98)$ & 0.043 \\
\hline \multicolumn{3}{|c|}{ Principal symptom precipitating admission } \\
\hline Chest pain $v$ other & $0.80(0.43,1.49)$ & 0.476 \\
\hline Reinfarction & $5.16(2.92,9.10)$ & $<0.001$ \\
\hline Recurrent chest pain & $0.98(0.57,1.71)$ & 0.954 \\
\hline \multicolumn{3}{|l|}{ Insurance } \\
\hline Chargeable & 1 & \\
\hline Veterans affairs non-chargeable & $2.17(0.90,5.27)$ & 0.085 \\
\hline Non-chargeable & $2.79(1.47,5.30)$ & 0.002 \\
\hline ACE inhibitor & $0.41(0.25,0.67)$ & 0.001 \\
\hline$\beta$ blocker & $0.29(0.17,0.50)$ & $<0.001$ \\
\hline Aspirin & $0.20(0.13,0.32)$ & $<0.001$ \\
\hline Intravenous heparin & $0.63(0.34,1.17)$ & 0.140 \\
\hline Intravenous nitrates & $1.42(0.86,2.34)$ & 0.161 \\
\hline Thrombolysis & $1.48(0.72,3.02)$ & 0.277 \\
\hline
\end{tabular}

${ }^{\star}$ For non-transferred patients the odds ratio $(95 \% \mathrm{CI})$ was $0.90(0.48,1.67)$ while for transferred patients it was $6.89(1.01,46.87)$. politan and non-metropolitan categories - only 20 of the 95 patients transferred to metropolitan hospitals had come from non-metropolitan hospitals (and all patients transferred to nonmetropolitan hospitals had come from within that category). The 233 transferred in patients were younger, more likely to be male, to have an anterior infarction, to have been admitted in cardiac arrest, to have a lower systolic blood pressure, to have had an admission for AMI in the previous three months, and to be nonchargeable than those admitted directly to the hospital of analysis. The crude mortality was higher than for the patients as a whole among the non-metropolitan transferred in patients at $15.2 \%$ and lower among metropolitan transferred in patients at $4.2 \%$ (footnote for table 2 shows mortality for non-metropolitan $v$ metropolitan by transfer status). Those transferred to non-metropolitan hospitals were significantly more likely than those transferred to metropolitan hospitals to have ST increase $(69 \%$ and $47 \%$ ), ST depression ( $68 \%$ and $44 \%$ ), cause of admission being chest pain ( $85 \%$ and $59 \%$ ), and significantly less likely to have been admitted with $\mathrm{AMI}$ in the previous three months $(3 \%$ and $21 \%$ ), and to have had a previous coronary angiogram ( $4 \%$ and $25 \%$ ). For the subgroup of patients transferred the odds ratio for seven day mortality for non-metropolitan relative to metropolitan was still marginally significant after adjustment for treatment variables (see footnotes for table 3).

\section{Discussion}

Our study found that after adjustment for disease severity, seven day mortality in nonmetropolitan hospitals was higher than in metropolitan hospitals in NSW. The use of cardiac medications is different between the two areas and the mortality difference was abolished when adjustment for these medications was made.

According to the 1994/95 hospital classification of the NSW Department of Health ${ }^{14}$ metropolitan hospitals are the hospitals located in metropolitan areas with a population of 100000 or greater (in NSW these reflect the Statistical Districts of Sydney, Newcastle and Wollongong). These hospitals include referral hospitals with referral and teaching services and District Metropolitan hospitals. Nonmetropolitan hospitals include District NonMetropolitan hospitals, which provide health care services to their local population, and Major Non-Metropolitan Referral hospitals, which function as referral hospitals for defined catchment populations outside metropolitan areas. The random sampling method of the Acute Cardiac Care Project selected 19 of 34 metropolitan and 28 of 49 non-metropolitan hospitals in NSW. This sample represents 57\% of the hospitals in each hospital type and therefore our results could be generalised to compare mortality rates after AMI between the two hospital types.

The selection of variables may influence the interpretation of differences in outcome between hospital types, therefore there is a need to adjust for the variables that contribute to 
hospital death, and particularly for any difference in disease severity. An ideal risk adjustment for severity might not exist, because of unmeasured factors in disease severity, ${ }^{19}$ although a number of severity adjustment models have been used in previous studies. ${ }^{716}$ Keeler $e t a l^{20}$ have suggested that a small set of clinical variables could explain a substantial amount of variance in death rates. In our study we adjusted for all measures of severity for which we had data. In the Medicare Mortality Prediction Study, ${ }^{17}$ the best predictors of mortality were age, mean arterial blood pressure, sub-endocardial infarction within 72 hours of admission, pulmonary vascular congestion and serum urea nitrogen level. In the study by Normand et $a l,{ }^{16}$ the four largest contributors to explain 30 day mortality rate were mean arterial blood pressure, age, respiratory rate and serum urea nitrogen level. A prognostic index for AMI created by Dubois et $a l^{21}$ included three factors: age, infarct position and left ventricular function.

In an attempt to explain the variation in mortality between the two hospital types, the use of cardiac medications needs to be discussed. Our study found that the use of effective cardiac medications was different between metropolitan and non-metropolitan hospitals, a finding consistent with the results of the study by Lim et al..$^{13}$ The addition of the treatment variables into the model resulted in the difference between outcome in metropolitan and non-metropolitan hospitals being reduced, suggesting that the use of these medications contributed to the difference in mortality between hospital types. Although the use of thrombolysis appeared lower in metropolitan than non-metropolitan hospitals, this was not statistically significant and we have separately shown that when adjustment is made for acknowledged indications for thrombolysis, the metropolitan/non-metropolitan rates of use are identical (D'Este et al, in preparation).

A previous study conducted in Illinois $(\text { USA })^{8}$ found similar results with a higher inhospital mortality in rural hospitals compared with that in urban hospitals. Another study $^{10}$ showed that cardiologists were more likely than generalists to use medications that have been shown to improve survival after AMI, and that better outcomes were achieved by cardiologists. In Australia, cardiologists are mainly in metropolitan hospitals, and a greater use of medications of proved benefit has been reported. ${ }^{13}$ This factor might be reflected by the less use of effective medications in non-metropolitan hospitals in our study, partly contributing to the difference in hospital mortality between non-metropolitan and metropolitan hospitals. In addition, a recent study by Thiemann et $a l^{2}$ has reported high volume hospitals had lower mortality after AMI than low volume hospitals. We have not analysed data on this factor, but metropolitan hospitals certainly do have more beds than nonmetropolitan hospitals.

In our study, 233 patients were transferred in from other hospitals. As the majority were transferred within their final metropolitan or non-metropolitan category, the hypothesis relating to differences in outcome according to whether they were admitted to a metropolitan hospital or not is best tested by including them in the analysis. These transferred in patients were more likely to have anterior infarction and cardiac arrest and had lower systolic blood pressure on admission, but they were younger, and more likely to be male. In addition, those transferred in to metropolitan and nonmetropolitan hospitals were very differentparticularly in their mortality rates. It is likely that the reason for transfer in non-metropolitan hospitals was that these patients were at the more severe end of the disease spectrum, with the opposite being the case among metropolitan hospital transfers.

As in any retrospective study, our study is limited by the availability of data-some factors considered as good predictors were not available in our dataset.

In conclusion, this study demonstrated marked lower seven day mortality among patients with AMI in metropolitan hospitals compared with those in non-metropolitan hospitals in NSW, Australia, after adjustment for patient severity. This variation seems to be partly explained by the difference in the use of effective cardiac medications between the two hospital types.

We are grateful to Ms Erica Morse for her excellent work as project manager and the nurses who collected the data.

Funding: SW Health provided the funds for this study. Conflicts of interest: none.

1 Kahn KL, Brook RH, Draper D, et al. Interpreting hospital mortality data. How can we proceed? $\mathscr{F} A M A$ 1988;260:3625-8.

2 Kahn KL, Rogers WH, Rubenstein LV, et al. Measuring quality of care with explicit process criteria before and after implementation of the DRG-base prospective payment system. ҒAMA 1990;264:1969-73.

3 Anonymous. Dicing with death rates (editorial). Lancet 1993;341:1183-4.

Orchard C. Comparing health care outcomes. BMF 1994;308:1493-6.

5 Dillner L. Scottish death rates published with health warnDillner L. Scottish death rates put
ing. BMF 1994;309:1599-600.

ing. $B M \mathcal{F} 1994 ; 309: 1599-600$.
6 Selker HP. Systems for comparing actual and predicted mortality rates: characteristics to promote cooperation in improving hospital care. Ann Intern Med 1993;118:820-2.

7 Keeler EB, Rubenstein LV, Kahn KL, et al. Hospital characteristics and quality of care. $\mathcal{F A M A}$ 1992;268:1709-14.

8 Hand R, Klemka Walden L, Inczauskis D. Rural hospital mortality for myocardial infarction in medicare patients in Illinois. Am F Med Qual 1996;11:135-41.

9 Casale PN, JonesJL, Wolf FE, et al. Patients treated by cardiologists have a lower in-hospital mortality for acute myocardial infarction. 7 Am Coll Cardiol 1998;32:885-9.

10 Jollis JG. Delong ER, Peterson ED, et al. Outcome of acute myocardial infarction according to the speciality of the admitting physician. N Engl F Med 1996;335:1880-7.

11 Fitzpatrick JM, Manderson L. Health at the margin: providing services in remote areas and for marginal populations. ing services in remote areas and for
Aust $\mathcal{F}$ Publ Health 1995;19:547-8.

12 Dobson AJ, Jamrozik KD, Hobbs M, et al. Medical care and case fatality from myocardial infarction and coronary death in Newcastle and Perth. Med f Aust 1993;23:12-18.

13 Lim L L-Y, O'Connell RL, Heller RF. Differences in management of heart attack patients between metropolitan and regional hospitals in the Hunter region of Australia. Australia and New Zealand fournal of Public Health 1999;23: 61-6.

14 New South Wales Health. NSW Public Hospitals Comparison Data 1994/95. Sydney: New South Wales Health Department.

15 Braunwald E. Heart disease: a textbook of cardiovascular medicine. 5th ed. New York: WB Saunders, 1997:1185.

16 Normand S-LT, Glickman ME, Sharma GRVRK, et al. Using admission characteristics to predict short-term mortality from myocardial infarction in elderly patients: results from the Cooperative Cardiovascular Project. $\mathcal{F A M A 1 9 9 6}$ 275:1322-8.

17 Daley J, Jencks S, Draper D, et al. Predicting hospitalassociated mortality for medicare patients- a method for 
patients with stroke, pneumonia, acute myocardial infarction and congestive heart failure. $\mathscr{f} A M A$ 1988;260:361623.

$18 \mathrm{ACC} / \mathrm{AHA}$ guidelines for the management of patients with acute myocardial infarction. A report of the American College of Cardiology/American Heart Association Task Force on Practice Guidelines. F Am Coll Cardiol 1996;28:1328428.

19 Boyce N, McNeil J, Graves D, et al. Quality and outcome indicators for acute healthcare services. Canberra: Australian Government Publishing Services, 1997:40-6.
20 Keeler EB, Kahn KL, Draper D, et al. Changes in sickness at admission following the introduction of the prospective admission following the introduction of
payment system. $¥ A M A 1990 ; 264: 1962-8$

21 Dubois C, Pierard LA, Albert A, et al. Short-term risk classification at admission based on simple clinical data in acute myocardial infarction. Am f Cardiol 1988;61:21619

22 Thiemann DR, Coresh J, Oetgen WJ, et al. The association between hospital volume and survival after acute myocardial infarction in elderly patients. $N$ Engl F Med 1999;340: $1640-8$. 